\title{
Notes on Operations
}

\section{Acquisitions Management in Changing Times}

\section{Carol Pitts Diedrichs}

There can be no doubt that this is a time of great change for libraries and librarians, particularly those in technical services. The management and business literature surrounding the topics of management and change has much to suggest and recommend to acquisitions managers struggling with rapid change. This literature can provide some insights into how those management theories and solutions can be applied to acquisitions. Three concerns are addressed here: What are the essential elements of change? How do acquisitions managers lead in this environment, particularly with those who report to them? How do acquisitions librarians cope with change?

$\mathbf{T}$

here can be no doubt that this is a time of great change for libraries and librarians, particularly those in technical services. Every acquisitions manager must face these issues. All need guidance and encouragement to get through these times, and no one has all the answers. However, the management and business literature surrounding the issues of management and change has much to suggest and recommend. This literature can provide some insights into how those management theories and solutions can be applied to acquisitions.

In particular, acquisitions managers are expected to cope with and become expert in new arenas such as document delivery, copy cataloging, outsourcing, and contract negotiation. New functions can include selecting and downloading the potential catalog record from bibliographic utilities at the preorder stage; completing cataloging on receipt where adequate copy exists; managing outsourcing contracts that combine approval profiles, cataloging records, and physical processing; and developing and managing document delivery programs that complement the traditional collection development process.

In the past, acquisitions focused on locating material and recording its bibliographic information correctly for the vendor rather than the patron. Although searching in a bibliographic utility may have been done in the past prior to placing orders, its primary purposes were to determine whether the title already existed in the library's collection and to acquire bibliographic data appropriate to identify the piece to the supplier. Now, preorder searching is done for additional purposes, such as correctly identifying the piece and its previous treatment in the library cata-

Canol Pitts Diedrichs is Head, Acquisition Department, Ohio State University Libraries (e-mail: diedrichs.1@osu.edu). This paper was originally presented at the ALCTS Acquisitions Section preconference titled "The Business of Acquisitions" in Chicago on June 22-23, 1995. Manuscript received February 15, 1996; accepted for publication March 25, 1996. 
log, or attaching the order for a new volume to the fully cataloged record for the entire set where earlier volumes already exist in the library's catalog. A corollary to) this searching is determining before use whether the order record added to the catalog for the ordering function will be usable copy for cataloging when the piece arrives.

Libraries such as the University of Cincinnati and the University of Kansas have combined the acquisitions function with document delivery programs. Acquisitions managers are now jointly involved with collection managers in determining when to purchase and how to account for an individual work rather than simply acquiring an entire issue for the collection.

Most acquisitions librarians fit the description of classic middle managers: they report to an upper administration but also have a number of staff members reporting to them. Change, reorganization, and reengineering often is imposed from above. However, by virtue of their positions, acquisitions librarians must respond to change initiatives from above as well as lead change efforts within their departments. In this paper, I will examine three questions:

1 . What are the essential elements of change?

2. How do acquisitions managers lead in this environment, particularly with those who report to them?

3. How do acquisitions librarians cope with change?

Key to answering these questions are the need to understand what the library and university administration is doing and why, and the need to understand the business theory surrounding change.

\section{Essential Elements of Change}

\section{EXTERNAL ENVIRONMENT}

One of the essential elements of the change process is becoming aware of the external environment. In essence, "managers who are good at creating sustainable change have an extensive understanding of the environment surrounding the business, where the main threats and opportunities lie" (Clarke 1994, 1). From my experience, there are certainly elements of the state environment that are driving change at Ohio State University (OSU). The university has been under heavy fire from the media and the governor in particular. The governor, who has a reputation for viewing higher education harshly, actually published an editorial in suburban newspapers that serve some suburbs of Columbus lambasting staff and faculty in public institutions of higher education for being lazy. Diminished state funding for the campus has resulted in departmental restructurings and elimination of programs.

During one budget cycle several years ago, the OSU Libraries' annual report, which is essentially a report on progress and a request for funding, had an entirely new wrinkle. The libraries were mandated to produce a report showing budget cuts of $4 \%, 6 \%$, and $8 \%$. The plan was to indicate where the cuts were to be taken and what impact these cuts would have. That portion is fairly predictable. The new wrinkle was that the plan was to indicate how the library would reinvest those savings in its own operation to improve services. If the university approved the plan, the libraries would be allowed to keep the savings to use in the manner indicated in the plan. If the library refused or failed to submit a plan indicating ways to cut, the administration would make the cut for them and keep the money. This is an excellent example of a mandate from the "environment" to look at things with a new eye and reengineer.

For acquisitions librarians, the external environment also includes the larger library environment. For example, at OSU a number of environmental changes have occurred. The 25-year-old LCS online catalog was recently replaced by an Innovative Interfaces, Inc. (III) system. In addition, $O S U$ is a charter member of the OhioLINK Project, which involves participation in a statewide union catalog and patron-initiated circulation throughout the state. Both of these automation activities created significant changes within the library system. The change from LCS to III involved a workload shift from management of the system by the 
university's systems staff to the libraries' automation staff. The university administration also decided, without consulting the library that the new system, had to be cheaper to maintain so that some of the libraries' allocation that was used to support automation could be returned. New demands from Ohiol.INK for patron-initiated circulation meant a commitment to forty-eight-hour delivery of materials requested by others in the state. This increased demand resulted in a significant new workload on circulation and mailroom staffs.

\section{ORGANIZATIONAL CAPABILITY}

A second key element of change is assessing the organization's ability to effect change. Managers must "diagnose [their] organization's capability to deliver the kinds of changes . . . the marketplace and external world demand" (Clarke 1994, 25). One of the most dramatic changes for technical services in the past few years is the extension of outsourcing to cover operations that have traditionally been done in-house. The best determinant of whether members in an organization are capable of evaluating and making such changes is their willingness to test new procedures and compare in-house costs to outsourced ones.

At OSU, the Acquisition Department and the Cataloging Department served as a beta test site for the OCLC Online Computer Library Center, Inc. (OCLC) PromptCat program. For a period of several weeks, tapes of short bibliographic records from the approval vendor were sent to OCLC for matching against their database. A printout of the records selected from the OCLC database through OCLC's matching algorithm was sent to the library. These titles were searched in the OCLC database by OSU staff to determine the record that would have been selected by OSU cataloging staff during usual copy cataloging. "Based on a random sample of 200 books, 182 records (91\%) matched one-to-one with those chosen by OSU" (Rider and Hamilton 1996, 12). With the library's low approval return rate and high hit rate against the
OCLC database for titles received on approval, the OSU Libraries determined that this program would be an effective means for decreasing the throughput time for one category of new receipts. The key point here is that the organization has to be willing to consider changes of this nature and evaluate their feasibility.

Part of organizational capability depends on organizational culture, also known as the corporate culture.

"Corporate culture" is the organizational equivalent of the fingerprint, the unique identification of every business in terms of its history, assumptions, values, and behaviors. Without a good understanding of the traditions that underlie a particular business it is all too easy to propose changes that completely go against the grain and will therefore be rejected by the body of the organization (Clarke 1994, 40).

\section{UNDERSTANDING THE \\ Change Process}

Of the myriad explanations of the change process, the one suggested by Swedish psychologist Claes Janssen is the most compelling. He suggests that "people's reactions to change involve moving through something akin to a 'four-room apartment" (Phillips 1995, 100). The four rooms-contentment, denial, confusion, and renewal-are not unlike the phases of the grieving process (another explanation often used for the change process). In the contentment room, people are comfortable with what is happening and able to keep things in perspective. People should not be moved out of this room unless it is absolutely necessary. Changes that involve job threats or reorganization usually send the individual initially into the denial room, where they do not accept their situation but appear oblivious to it.

Individuals move into the confusion room when they own up to their fears. At this stage, individuals feel unsafe and insecure and often lack a clear sense of direction. The only way out of this room is to accept that this confusion is the only way to get to the renewal room. The individuals in the renewal room are able to 
accept the new and begin to experience the excitement of positive change. Individuals remain in the contentment room until the next change arrives, and the process recurs (Phillips 1995, 103). This explanation is compelling because it emphasizes the reality that one never leaves the apartment itself; one only moves through the rooms continuously. "This reflects the idea that change is not a downward spiral, but a perpetual circle" (Phillips 1995, 100).

\section{How Individuals WiLl REact To the Change Process}

In The Essence of Change, Liz Clarke provides a list of thirteen positive responses to change such as enthusiasm, challenge, excitement, reward, fulfillment, and new start. She presents thirty negative responses to change such as fear, anxiety, shock, distrust, stress, loss of selfesteem, depression, insomnia, conflict, mutiny, and personality change (Clarke 1994, 76). Obviously, it is not very difficult to deal with those individuals who respond positively to change. It is resistance that poses the greatest problem for managers. Kanter (1985, 52-56) has articulated the ten most common reasons that people resist change:

1. They feel a loss of control because they feel powerless.

2. They feel excess uncertainty because they don't know what is going to happen next.

3. They feel surprise because decisions or requests have been made without appropriate preparation or groundwork.

4. They question familiar routines and habits (known as the Difference Effect).

5. They fear that admitting that the way things were done in the past was flawed and will result in a loss of face.

6. They are concerned about their future competence.

7. They fear other disruptions as a result of this change.

8. They resist an increased workload.

9. They transfer past resentments to requests to do something new.
10. They fear they will lose their jobs, their status, or their power.

Curzon (1989, 89-90) adds some additional reasons for resistance:

1. Ignorance, When staff lack the information to persuade them that the idea is a good one.

2. No confidence in management. In this case either the manager is not trustworthy or the staff is predisposed to cynicism about management.

3. Peer pressure. There may be pressure from fellow co-workers to go with the group reaction.

4. Poorly managed project. Staff may resist when they feel that the project is disorganized, poorly thought out or suffering from bad decision making.

The reason for including this long list is to dispel a widely held notion that the primary reason for resistance is that the individual feels threatened. This "excuse" shifts the burden from the manager to the individual and enables the manager to dismiss the individual's concerns as "feeling threatened." In reality, managers should look carefully at the other factors and make adjustments when possible.

Each acquisitions manager's environment is very different. Resistance to change can manifest itself in a number of ways, depending on the particular corporate culture (Curzon 1989, 87-88):

1. Work slowdown. Rather than confronting the manager directly, an individual or group of staff might use passiveaggressive behavior.

2. Union action. Union members may go to the union, particularly if the change involves salary or working conditions.

3. Gossip. Gossip is the most common way to show resistance and is a form of sabotage.

4. Setting up alternate systems. Staff may set up alternate systems or simply keep working in the old way rather than implement the change.

5. Refusing to learn a new task.

6. Giving surface support. In this covert resistance, the staff member pays lip service to the new idea but actually does not comply with the change. This individual may be wary of speaking honestly or of openly defying the manager. 
7. Dragging out the work. Missed deadlines or issues that never get out of committee are examples of this type of resistance.

8. Providing inadequate resources. This is the weapon of a supervisor who is resisting change. There are always excuses for resources being used elsewhere rather than in pursuit of the change; and

9. Giving mixed messages. Another weapon of the supervisor. If the supervisor gives an idea short shrift, so will the staff.

How then do acquisitions managers counteract this resistance (Curzon 1989, 90-92)?

1. Create a safety net. If fear is the issue, provide as much training, meetings, and information as possible.

2. Manage the change well. Have a wellorganized and well-considered approach to the change. Staff will respond to quality work and strong leadership.

3. Be an example. While the manager may be doubtful privately, set an example by being positive, assertive, enthusiastic and confident about the change.

4. Make the resisters part of the project. This is difficult but a manager can often convert doubters by including them more closely in the change process. However, the manager runs the risk of the project being changed by their actions or stalemated.

5. Use peer pressure. If only part of the staff is resistant, the supporters can be encouraged to exert reverse peer pressure on the resisters.

6. Be honest. There will be less resistance if the manager has a reputation for honesty.

7. Communicate. Managers should speak often and frankly about the change. Staff should feel free to speak up.

8. Discipline. If everything else has been tried, counseling and warning about behavior may be justified. This is a last resort.

Fortunately, most of the resistance to change that I have experienced has been on a small scale, usually an individual responding to a particular change in his or her position.

\section{EMPOWERMENT}

Empowerment is one of the goals of most change processes today. Empowerment can "make [the] work force more productive without sacrificing essential leadership and controls" (Price Waterhouse $1995,94)$. But what does empowerment really mean? There is a common misconception that empowerment means giving power away. "Empowerment is the creation of an environment in which employees at all levels feel that they have real influence over standards of quality, service, and business effectiveness within their areas of responsibility" (Price Waterhouse 1995,95 ).

Staff members who are empowered exhibit a number of behaviors (Price Waterhouse 1995, 102). They:
1. Present ideas
2. Take on problems
3. Build on colleagues' efforts
4. Help to implement
5 . Seek out information
6. Encourage discussion
7. Work well in a team
8. Take initiative
9. Build realistic ideas
10. Help to sustain environment
11. Challenge
12. Contribute ideas

It is likely that many of the individuals in acquisitions already exhibit some, if not all, of these behaviors. Managers must learn to foster these qualities to manage effectively in changing times.

\section{LEADERSHIP}

On of the greatest challenges each acquisitions manager faces is leading their staff during times of change. Curzon has indicated that "change that is out of control or mismanaged can prove destructive to any organization" (Curzon 1989, 13). Hale and Williams $(1989,11)$ have identified five critical issues that a manager involved in the change process must address:

1. Deliberately selecting a future state that will meet long-term needs

2. Providing quality service while changes are in process 
3. Building momentum and commitment necessary to set changes in motion

4. Orchestrating all the resources for the change

5. Caring for the human element-feelings of anxiety, resistance or excitement

The last element rests squarely on the shoulders of the acquisitions manager involved in the change process. Because acquisitions managers are usually middle managers and not upper-level management, they might not have primary responsibility for the change process. But they certainly have responsibility for the well-being and productivity of their staff. In this role, acquisitions managers need to (Curzon 1989, 31-37):

1. Listen to and respect staff.

2. Maintain a healthy balance between task and people.

3. Be fair with everyone.

4. Be supportive.

5. Be committed.

6. Be trustworthy and open.

7. Be collegial.

8. Be credible.

\section{Managing: the ACtual Chance Process}

The following list is a set of sixteen principles to employ when the acquisitions manager has primary responsibility for managing the change process. They are my amalgamation of a number of lists from several sources (Price Waterhouse 1995, 4-7, 45, 57-59, 75-76; Clarke 1994, 174; Curzon 1989, 122). Managers should:

1. Confront reality. Organizations have to change, regardless of whether outsourcing is the solution. Managers of technical services operations must recognize that they must produce more and faster than in the past. Material must reach the shelves faster.

2. Focus on specific outcomes. Managers must focus efforts where the paybacks are the greatest. Incremental improvements in the quality of cataloging are probably not an adequate payback for the resources invested.
Getting a rush book in time for a professor to use on the first day of class (regardless of the cost) will have a more obvious payback.

3. Set an appropriate scope. Managers must focus on measurably improving performance in areas most important to their organization, e.g., delivering newly received serial issues to the location within 24 hours of receipt.

4. Build a powerful case for change. Not everyone is prepared for change. Managers may have to build the momentum and support for needed changes. When no crisis exists to make the case for change, managers must focus on the values and benefits to be gained through the change. A number of crisis situations were mentioned earlier (e.g., loss of key staff) that drive the change process, but crisis need not be the only change initiative at work.

5. Let the customer drive change. For acquisitions the first-line customer is usually the collection manager, but the ultimate customer is the user. Technical services must "eliminate activities that do not add value from the customer's viewpoint" (Price Waterhouse 1995, 124).

6. Know the library's stakeholders. Managers must understand the needs and priorities of those who have a vested interest in the changes being considered.

7. Communicate continuously and honestly. Communicating what is ahead or being planned can help mitigate resistance. Keep no secrets; strive for consistency. The actions of managers must be consistent with their words. I remember being told often as a child by my mother that "beauty is as beauty does." Action is the most persuasive and visible measure of the honesty of leaders.

8. Reshape the area's measures or statistics. Managers must design new performance measures consistent with new goals and strategies and dismantle old measures when they are no longer needed. 
9. Build skills. Managers must invest in human resources. Broaden the technical, problem-solving, leadership, and decision-making skills in individuals at all levels.

10. Develop a formal plan. It should outline the evaluation process as well as the decision-making process.

11. Integrate your initiatives. Change initiatives occur throughout an organization. Managers must try to maintain a coherent approach to the change process and not diminish energy by undertaking too many diverse approaches or agendas at one time.

12. Link how the individual "wins" with the change program. Managers must show individuals how they can participate in the change process and make that participation substantive. For example, staff in lower-level positions may now get to do more interesting work than before.

13. Clarify and question understandings. Confusion causes inaction. Encourage individuals to ask for clarification. Many will not ask, however, so it is best to overcommunicate. Make no false promises.

14. Slay sacred cows. One of the biggest disappointments in the change process is to have the administration set aside particular sacred cows that are not to be considered. Virtually any manager can list those individuals or departments within the library that are off limits. These are the folks who take no budget cut (or a modest one) when everyone else is receiving a heavy hit. If library management is really committed to the change process, slay a sacred cow!

15. Budget lots of time. Change takes longer than anyone expects. It is an evolutionary process, not a revolutionary one.

16. Consider the political realities. Despite the manager's best intentions and hopes for a pure decision-making process, political realities are just that-realities. By taking them into consideration from the beginning, managers might avoid establishing false hopes.

\section{MAKING The DECISION}

The manager in charge of the change process is the manager who will be making the decision about the change or at least participating in that decision-making process. That manager should, according to Curzon $(1989,65-71)$ :

1. Review all documents. There is nothing more offensive than to receive news of a final decision in which it is obvious that no one even bothered to review the recommendations or comments of the group charged with evaluating the issue.

2. Evaluate the pros and cons.

3. Consider the consequences. Curzon states that "A decision cannot be separated from its consequences."

4. Allow for mature deliberation. "Mature deliberation can be defined as a period of time in which the project is allowed to rest so that thinking can ripen. Change frequently has an impulse all its own. People get caught up in it and begin to believe what has been set out regardless of contrary evidence."

5. Avoid major barriers to decision making. These can include insufficient facts, projected attitudes and values, opportunism, pressure, or the desire for perfection.

6. Make the right decision (Curzon 1989, 65-71).

Clarke $[(1994,170)]$ has compiled the "Ten Commandments for Getting It Wrong:"

1. Criticize your predecessor: he or she screwed it up.

2. Don't tell anyone anything until you've spelt out the last detail.

3. Tell lies.

4. Impose a communications blackout.

5. Announce a change, then try to get it to work.

6. Time major changes for the Friday afternoon before Christmas.

7. Be autocratic: Genghis Khan didn't consult.

8. Discourage people from criticizing the status quo and saying what they think; you might not like the answers.

9. Rely on memos: talking is a waste of time. 
10. Don't forget it's your change not theirs.

All managers would like to believe that they have never done any of these things or something like them, but unfortunately many of them probably have. For example, I reorganized the accounting division I once supervised because of a very serious problem with the supervisor of that unit. Indeed, I made all of the decisions and discussed them with the other division heads who would be taking on some new activities, but I never talked to the individuals who were being reassigned or the supervisor. Then I announced the change to everyone at once. I console myself in this case with the confidential nature of the issues causing the change, but I know I probably suffered a blow to my credibility with some individuals in the department with that action. Most now understand the necessity of my actions, but it has taken some time and experience to regain the ground lost.

\section{Thinking: BIg, Thinking NeW}

"People need to feel free to take the lid off, to think out of the box, to surface dozens of ideas that may not work in order to come up with a few that are genuinely powerful" (Price Waterhouse 1995, 6). They warn managers to be careful not to sit on a new idea too quickly because it may inhibit individuals from coming forth with other more appropriate ideas. Rosabeth Kanter's famous spoof recipe for creating inertia, "Rules for Stifling Innovation," follows (Clarke 1994, 110-11):

1. Regard any new idea from below with suspicion because it's new, and it's from below.

2. Insist that people who need your approval to act first go through several other levels of management to get their signature.

3. Ask departments or individuals to challenge and criticize each other's proposals. (That saves you the job of deciding; you just pick the survivor.)

4. Express your criticisms freely and withhold your praise (that keeps people on their toes). Let them know they can be fired at any time.
5. Treat identification of problems as signs of failure, to discourage people from letting you know when something in their area isn't working.

6. Control everything carefully. Make sure people count anything that can be counted, frequently.

7. Make decisions to reorganize or change policies in secret, and spring them on people unexpectedly. (This also keeps people on their toes.)

8. Make sure that requests for information are fully justified, and make sure that it is not given out to managers freely. (You don't want data to fall into the wrong hands.)

9. Assign to lower-level managers, in the name of delegation and participation, responsibility for figuring out how to cut back, lay off, move people around, or otherwise implement threatening decisions you have made, and get them to do it quickly.

10. Above all, never forget that you, the higher-ups, already know everything important about business.

Thinking big, thinking new means overcoming conventional wisdom. Conventional wisdom is more than just "we've always done it this way." A good example in the area of acquisitions is included in the recent report from Stanford University on the reengineering of their technical processing. Large university libraries usually engage in approval purchasing programs that include a time period for review by collection managers. During this review process the books can be accepted or rejected. The conventional wisdom is that, because no purchase order was issued to "select" the title before it arrived, the library needs to do a review process before accepting it into the collection. Thinking new may mean reevaluating whether the number of returns is small enough that it makes more sense simply to keep the books rather than to review and return the small percentage of inappropriate ones. This possibility can be given serious consideration in an environment in which the materials budget is better funded than the staffing budget.

Southwest Airlines is an excellent example of thinking big, thinking new. Their 
frequent flyer program ignores the usual conventions of such plans. When individuals sign up for the Southwest Airlines plan, they are handed applications with sixteen empty squares on the application. The agent will stamp the application each time the individual takes a Southwest Airlines flight. The difference is that this information is not stored in a computer somewhere; passengers have to remember to carry the application with them every time they take a flight. When the 16 squares are filled, the passenger becomes a member of the program and immediately receives his first reward: a free ticket. The airline has shifted the information processing duties to the customer without any disruption in customer service. In addition, many customers lose their application after 5 to 6 boxes are stamped and Southwest saves money and passes (Price Waterhouse 1995, 158-59).

The final piece of thinking big, thinking new is asking "what if" (Price Waterhouse 199,1625 ). This is an excellent way to operate on a daily basis as managers make decisions or evaluate old patterns. What if an expensive order did not have to go through three levels of approval signatures? What if collection managers stopped signing their initials to order requests? What if orders were keyed directly into the online system rather than being provided to Acquisitions in paper form? What if collection managers could order material just by initialing beside the title in the catalog? What if serial issues were not checked in but simply sent to the shelves? What if invoices were paid without checking to see whether all pieces had been received? What if invoice statements from vendors were never reviewed? With some of these, there would be consequences if the action did not occur. But, in other cases, the consequences would be nonexistent or within tolerable levels.

\section{Change Starts with The Manager}

Thus far I have focused on managing change, motivating staff to change, etc., but one person has been left out: the ac- quisitions manager. Acquisitions managers can be one of the most important factors for change in their attitudes, enthusiasm, vulnerability, and willingness to change themselves. When radical change occurs, the old way of doing things may no longer work. Instead, managers have to radically reexamine and throw out old assumptions. The classic adage that has been attributed to Rosabeth Kanter is that "change is something the top asks the middle to do to the bottom.' This assumes that the person 'doing' the change can sit safely on the point of the organization pyramid orchestrating the process while those at the front line get changed. A fatal illusion. In making any change-personal or organizational-you risk yourself" (Clarke 1994, 49).

It is also important for managers to believe that they can make a difference. Individuals have the most control over themselves, but the hardest person to change is also oneself. Many managers avoid making changes until something significant in their lives changes. Clarke discusses another list that resulted from work done at Ashridge Management College on managing change. A few examples follow:

For me to change I am waiting for (Clarke 1994, 50-51):

inspiration, my turn, revenge, time almost to run out, a more favourable horoscope, someone to be watching, my subordinates to mature, my self-esteem to be restored, a clearly written set of instructions, a signal from heaven, the stakes to be lower, someone else to screw up, logic to prevail, and on and on ...

Managers have to let go of the old even though there may be no guarantee of what the new will bring.

\section{SELF-ASSESSMENT}

Much has been written on personal growth; Bones (1994) provides particularly useful information and exercises for assessing one's current position and keeping oneself motivated and stable during times of massive change. These exercises can be done alone, but many would be useful if used with the staff being supervised. One of the first steps is to take stock 
of where you are. For example, ask yourself, In thinking about my library and department, what are the five major peoplebased issues facing us (Bones 1994, 5)? For example, OSU recently faced the retirement of six librarians, many of whom had key collection development or management roles or specific skills not readily replaceable. skills:

In a second step, evaluate your own

1. What major tasks am I expected to carry out?

2 . What skills do they require of me? For example, technical/professional, critical/analytical, or reporting managerial/supervisory interpersonal (Bones 1994, 17-18).

3 . What new skills are needed to be successful in my job?

4. What actions can I take to go about acquiring these skills?

Even more important than skills is the way in which the manager spends his time. Several years ago, I began thinking about how I spent time each day. For a period of two months, I kept daily track of how my time was spent in increments of fifteen minutes in forteen categories. These categories included general administration/ mail, meetings, word processing/ writing, specific committee assignments related to OhioLINK, e-mail, editing a journal, teaching in the Kent State library school program, ALA activities, professional reading, and research.

I was amazed by the average number of hours I was working each week as well as the areas where that time was being spent. In many categories, there was absolutely nothing I could do to change the amount of time being spent. In other areas, I did have more control, such as professional reading and meetings. For example, in order to give my staff more time to do productive work, I recently moved from a weekly meeting with my division heads and section heads to a biweekly meeting. This has proven successful and has added three hours a month of productive time back into the schedules of twelve people.

Continuous self-development and learning is essential in today's world. Each of us must take charge of our own devel- opment. "An individual who comes up with their own ideas for improvement is far more likely to see it through to the end, and to employ the new skills they have acquired on a regular basis. How many people do you know who have taken up golf later in life and are out in all weathers as they try to improve their handicap?" (Bones 1994, 31). Think back over the past ten years and identify several key achievements you are particularly proud of and several where you failed to achieve a goal. Ask yourself:

1 . What was your achievement?

2. How did you achieve it?

3. What skills did you use?

For the failures, ask yourself

4. Why did you fail?

5. What skills did you lack?

Review the lists. Did any skills appear more than once? In the failures, what skills could you have applied in order to succeed? Were there any surprises (Bones 1994, 31-36)? Sometimes we make bad decisions because we are too far removed from the details of a particular task. I am convinced that one of the best ways for managers to learn about the operations under their supervision is for them to perform those jobs themselves on occasion. The closer managers get to the activities, the easier it will be to see where improvements and changes can be instituted and, conversely, where suggested changes are not warranted.

Managers must also learn the importance of risking the impact of innovation rather than staying with what is safe.

Creativity can liberate organizations. We have to begin to establish management styles that welcome and encourage the innovative and that support the taking of risk. A key part of this is to set up learning processes that review the implementation and results of innovation, and, where failure occurs, ensure key points are understood and that the organization as a whole henefits from the experience (Bones 1994, $55)$.

\section{STRESS}

Even in the best of situations, managers are subject to a great deal of stress. In 
times of change, that stress accelerates and has even more serious consequences. "One of the most important sources of stress, . . . is responsibility for other people. The jobs that have been found to carry the highest levels of stress-miners, police officers, construction workers, doctors, dentists, and managers-all involve a high degree of responsibility for the safety and well-being of others" (Phillips 1995, 125). In addition to dealing with the stresses of their staff, managers also must deal with stresses in their own role. Overwork presents another struggle as does coping with conflicts and demands. However, it is important to remember that long hours do not necessarily result in higher productivity. People become too tired to think clearly and act effectively. Managers must be aware of the stress they are under and of the options available to reduce it (Phillips 1995, 125-30).

The following example illustrates how individuals can decide what is most important in life. This example concerns an overworked manager faced with his child's illness.

The manager dropped everything at work, spent three days at his son's hospital bed, and then returned to work to await further medical tests. He arrived at his desk, looked at the mounds of paper that had accumulated over three days, and suddenly realized that the paperwork "did not amount to a hill of beans" in comparison to the health of his son. It was as if someone had opened a window for him. With a wider perspective, and able to see the whole forest insteid of just the trees, he was able to get through his mound of paper in no time. He felt calmer and more able to cope. When the medical tests gave his son a clean bill of health, he did not lose his newfound perspective, and he felt far more efficient as a result (Phillips 1995, 131).

Another way of looking at this is to evaluate individual projects (especially when they mean working late) in terms of whether anyone would even know they had been done or would remember very long. That test can be used on many occasions to assess one's workload. Phillips (1995, 131-32) states:
Recharging the hatteries can take many forms depending on individual taste... Whatever form of relaxation you decide to adopt, the really important thing is to decide what things make life worth living for you.... Overcommitment to work does not mean more productivity. It creates managers who have tunnel vision. Managers who have a balanced outlook on work have a better perspective and are of more commercial value to the organization.... People with a clear sense of their own priorities are generally also better able to cope with change. ... Their internal "stability" will often have a trickle-down effect on the people they work with, making them calmer, too. Stressed managers tend to produce stressed teams or departments, but the reverse is also true: Self-aware, calm, and focused managers can produce a healthy department, able to respond positively and innovatively to change:

\section{ConCLUSION}

Libraries can expect lots of change for many years to come. Acquisitions cannot expect $t o$ be spared. Acquisitions is already becoming comfortable with recent changes, such as the addition of new functions. Entirely new functions that may at first seem unrelated to acquisitions will be aligned with it, such as interlibrary loan and document delivery. Some acquisitions departments have taken on expanded responsibility for negotiating licenses for the purchase of electronic products; this growing expertise may result in acquisitions becoming the contract and licensing center for the library. Acquisitions will be expected to build on its established competencies. For example, if the automated system can be used to track payments and budgets for a large materials budget, perhaps that expertise can be expanded to track individual faculty document delivery accounts. New subscription services such as RoweCom's Subscribe system open new avenues for the electronic transfer of funds between suppliers and the university. New approaches to collection development may result in approval material being accepted without review by collection managers, opening the door to ac- 
quiring this material not only fully cataloged but also with its physical processing completed by the vendor. All of these opportunities require an organization, and specifically an acquisitions manager, comfortable with leading and managing in times of change.

Change is inevitable and accelerating every day. Some organizations have experienced a continual change process or a stream of "flavor of the month" management fads. However, new management theories are not all just fads or clichès. The biggest problem is that we do not read all the details and follow through. We focus on the vanilla highlights and forget that chocolate sauce is what turns ordinary ice cream into a sundae.

\section{Works Cited}

Bones, Chris. 1994. The self-reliant manager. London: Routledge.
Clarke, Liz. 1994. The essence of change. New York: Prentice Hall.

Curzon, Susan C. 1989. Managing change: A how-to-do-it manual for planning, implementing, and evaluating change in libraries. New York: Neal-Schuman.

Hale, Sandra J., and Mary M. Williams, eds. 1989. Managing change: A guide to prodacing innovation from within. Washington, D.C.: The Urban Institute Pr.

Kanter, Rosabeth Moss. 1985. Managing the human side of change. Management review 74: 52-56.

Phillips, Nicola 1995. From vision to beyond teamwork: 10 ways to wake up and shake up your company. Burr Ridge, Ill.: Irwin.

Price Waterhouse Change Integration Team. 1995. Better change: Best practices for transforming your organization. Burr Ridge, Ill.: Irwin.

Rider, Mary M., and Marsha Hamilton. 1996. PromptCat issues for acquisitions: Quality review, cost analysis and workflow implications. Library acquisitions: Practice \& theory 20: 9-21. 